\title{
Simon of Genoa and Medieval Medicine
}

The history of medieval medicine has long been tied up with the discovery and editing of texts.

As with medieval history in general, scholars like De Renzi and Daremberg in the mid nineteenth century found it necessary to delve into archives and manuscript collections to supplement what was meagrely available in the form of printed books. The creation of a documentary basis for medicine was one of the central tasks of these pioneers, and was further established from the $1880 \mathrm{~s}$ onwards by Karl Sudhoff, the dominant figure in the history of medicine for half a century. The pages of Sudhoffs Archiv and the Mitteilungen zur Geschichte der Medizin, to say nothing of the Abhandlungen of his Leipzig Institute, are filled with editions and texts of all kinds, both large and small. Pupils and admirers around Europe followed his example. Even Henry Ernest Sigerist, his Leipzig successor who is now famous for his work on the social aspects of the history of medicine, began his academic career as an editor and cataloguer of medieval texts.

Sudhoff himself concentrated on two sorts of text: tracts and documents relating to the Black Death and other epidemics, and the archival evidence for the development of university medicine. His example laid the foundation for all subsequent studies of medieval ideas on epidemics, as well as of the institutional development of universities across Europe. He was less concerned with the actual university lectures that were delivered (a gap that has only partially been filled since his death), particularly in France and Italy, but interested instead in the history of institutions, notably hospitals; investigating the role of medicine in society rather than the intellectual pursuits of its leading practitioners.

Where scholars continued to take an interest in texts and in editing, they fell into two groups. The first was that of the classicists, concerned with fixing the manuscript base of their editions of ancient texts, principally Hippocrates, Dioscorides, and Galen. But these were Greek authors, and although familiar names in the Latin West, they wrote in Greek and, on the whole, their medieval Latin translations contributed little to the reestablishment of their original texts, particularly because the most influential texts of the time were translated into Latin from an Arabic translation of the original Greek. The one exception was the brilliant word-for-word versions of the South Italian, Niccolò da Reggio. Beloved of editors, his translations offered a way of regaining the very words of Galen, even if the Greek had been lost. But his translations, produced in the first half of the fourteenth century, came at a time when university courses were already 
standardized, and when few, even among the professors, bothered to read deeply into works that fell outside the curriculum.

The second modern group of medievalists concentrated on writings in the vernacular, particularly in English or German. They showed how the ideas of the learned physicians filtered down through society and how non-Latinate surgeons could develop their own sophisticated ideas on treatment. Recipe collections and short handbooks for the laity provided a bridge between elite and popular medicine.

Over the last thirty years there has been a revival in the study of medieval medicine. There have been major studies of medicine in Spain, Northern Italy, Paris, and England, to say nothing of a flood of controversial books on the Black Death. Textual studies have also flourished, not the least because of the linguistic interest in translations, particularly into Middle English. There have been regular conferences dedicated to Middle English texts, as well as to Latin medical texts from antiquity, with consequent publications of a variety of new material. Medicine pre-1000 AD in the Latin West has benefited from the researches of Klaus-Dietrich Fischer, among others, while codicologists and palaeographers have found many new texts in libraries both familiar and unfamiliar. Indeed, some of the more spectacular Latin finds have been made in the largest collections, where the disdain for, or unfamiliarity with, medieval medicine had frequently relegated manuscripts of this sort to the back of the queue for cataloguing. If one also considers the abundance of material now available online, from repertoires of manuscripts to photographs of the manuscripts themselves, the possibilities for scholarly progress in medieval medicine are enormous.

One must always remember, however, that a modern academic's understanding of medieval medical texts is likely to be very different from that of a medieval physician. The world of books, to say nothing of computers, is very different from that of manuscripts. That of abundant access to information fleetingly searched for minor queries can scarcely be compared to one in which a small number of texts were studied in enormous detail as the very foundations of a learned discipline. Few physicians in the Middle Ages, let alone their patients, possessed a library as full of relevant texts as a modern professor, and Latin, rather than their own vernacular, was the language of learning. Sources in Greek, Arabic, and Hebrew were inaccessible to all but a few, often aided by intermediaries with one or more of these languages as their native tongue. As a consequence, physicians had to rely on digests of various kinds to supplement the few texts at their disposal, some summarizing the essential points of Galenic doctrine, others providing a shortcut to therapeutic advice that had stood the test of generations, others creating short dictionaries for their own or others' use.

Despite their obvious significance, relatively little work has been done on these digests and repositories. Julius Pagel's editions of the dictionaries of two French physicians three generations apart, Johannes de Sancto Amando (1894) 
and Petrus de Sancto Floro (1896), are far from easy to use, even if modern technology has made them more accessible. Others, like Simon of Genoa, remain only in fallible printings from the Renaissance, a handicap to understanding the part they played in the transmission of medical knowledge around medieval Europe and, more importantly, from Classical Antiquity, via the Islamic world to the West.

The Simon of Genoa project, of which this volume forms a part, aims to provide a scholarly edition of his medical dictionary based on a collation of relevant manuscripts and early printed editions. The preliminary text, based on a 1510 printing, not only provides a more secure foundation for study, but also allows for a more precise investigation of his sources, which in turn may assist the editors of the texts and translations upon which Simon drew for his dictionary.

Sometimes, as in Valerie Knight's paper on Simon's use of the Latin Alexander of Tralles, one can come close to an identification of the actual manuscript, or at least manuscript family, on which he depended. Sometimes, as in Siam Bhayro's study of his use of Arabic sources, philology can throw light on the sort of Arabic that his Latin translator was using. Caroline Petit, in turn, focuses on Simon's use of a relatively rare portion of Galen, Book VI of his tract on simple drugs, to argue that he was using a Latin translation from the Arabic, and that, although there are copies of the original Greek text in circulation in Southern Italy, he did not take advantage of them. Indeed, as with Arabic, Simon's knowledge of the original language is far from clear, although he did know some Greek and he cites some unusual sources. More complex, as Marie Cronier shows, is his use of the Greek pharmacologist Dioscorides. In Simon's dictionary it is his description of plants that matters, not his assessment of their therapeutic properties. His sources for this author were almost certainly not directly Greek: both the references to a Greek codex and to illustrations in a Greek source are open to question, though that may not mean that he read widely into them. Instead, he relied largely on two different Latin translations, made at two different times. His main source is an arrangement of Dioscorides in alphabetical order, an obvious advantage for a dictionary writer, adapted from one of the three early Latin versions, the so-called 'Version C'. He also uses Version C itself, which is quite rare, but less frequently, and when he does, he often refers to it as being 'the real Dioscorides'. When his two sources conflict or fail, he has recourse to quotations in Latin from another tract ascribed to Dioscorides, On feminine herbs, which contains fragments taken from an even earlier Latin version, Version $A$, which he describes as coming from an 'old book'. Finally, he also makes use of quotations from Dioscorides in a text coming from Arabic, the so-called 'pseudo-Sarapion'. He himself may not have known Arabic to the extent of being able to read a long and complex book, but he seems to have set eyes on a copy of Dioscorides in Arabic with illustrations. Where he did so is unclear, but it is most likely to have been in Spain and the result of his friendship with the Jew Abraham of Tortosa. But although he gives 
a detailed description of what he saw, it cannot be easily reconciled with any existing manuscript. Similarly, his comments on a Greek illustrated manuscript do not fit the two major Greek manuscripts of this author that were in Southern Italy at this date. Analyzing his debt to authors closer in time is less difficult, simply because we can be sure that Simon had access to all the major Latin works of his day. As Charles Burnett shows, one of his main sources was the Breviarium of Stephen of Antioch, a digest of the new Arabic medicine in Latin dress.

Perhaps three quarters of Simon's entries in his dictionary deal with pharmacology, as Bouras-Vallianatos shows. His interest here is lexicographical rather than therapeutic, setting out a guide to what plants there are rather than analyzing their uses. This was not an easy task, because the variety of sources, not to mention the variety of languages on which they drew, was a source of confusion for centuries. The vagaries of medieval transmission only added to his difficulties, and his failure to always resolve them should not disguise his considerable talent in using and selecting the information at his disposal. The creation of a dictionary from what he had on hand was no easy feat.

Analyzing his sources is only the first stage in setting Simon in his intellectual context. He was a physician at the court of Pope Nicholas IV, and he had earlier collaborated with the Spanish Jew, Abraham of Tortosa, in the Latin translation of pseudo-Sarapion's Liber aggregatus. His origin in Genoa, a major Mediterranean trading city, would perhaps have brought him into contact with those who had visited Byzantium and the Greek settlements of Southern Italy, and it is perhaps from them that he derived his information on some Greek material that appears to be lost today. His papal connections would doubtless have also helped him, although at this stage the medical holdings of the papacy may not have been extensive or even accessible. His major conduit of information about Arabic sources is more likely to have been Spain than Sicily or the Maghreb.

As Peregrine Horden argues, our knowledge of Western medical culture, both inside and outside Rome at this date, is still far from complete, and it would be wrong to confine Simon's interests (and those of his fellow courtiers) solely to therapeutics. There were many new developments, from the provision of hospitals to autopsies. The growth of medical faculties in Italy and Southern France was just beginning and, though it was well established twenty or thirty years later, it was unclear which texts would be agreed upon to study. Although new Latin translations of Galen direct from Greek had been made, most doctors still relied on earlier versions, mainly from the Arabic, and on a handful of shorter texts that became known later as the Articella, The Little art of medicine. For therapeutics, the major sources were the great Arabic compendia that had been translated, mainly in Spain, during the early part of the century: Avicenna's Canon chief among them, as well as the older Salernitan Gariopontus. There was a fluidity in 1280 that was not there fifty years later. 
But, educated though Simon was, with greater access to scholarly medicine than most of his contemporaries, he was no haunter of cloistered libraries. His dictionary reveals his activity as a traveller and his willingness to talk to the local inhabitants, at times in their own language. Some of his information on plants comes from conversing with Greeks, probably in Southern Italy, although both Genoa and Rome attracted traders from those regions. As Zipser points out, he seemed to have spoken with Arabic speakers in Spain, although whether he met the woman from Aleppo who told him the name of a plant there, or even on a visit to the Eastern Mediterranean, is not clear. What is obvious, however, is his willingness to gain knowledge from whatever source, without restricting himself to learned tomes, as well as his scrupulous recording of what he was told. He takes an unusual interest in the spelling and pronunciation of non-Latin words, sometimes so carefully that one may even detect regional dialects. His knowledge of plants in particular is not bound by the cover of his book.

Philology, as in these papers, serves a dual purpose: not only to present an accurate text but also to delineate the written sources that he used. Together they allow the historian to go further, and build up a picture of Simon as an educated man, as a traveller, and as a doctor. What he chose to include was only a selection of what he knew; chosen and organized for the benefit of his fellow doctors. One begins also to dimly see something of what he was; a good listener, an avid reader, and the sound organizer of a book that continued to be used for several more centuries to come. 
